\title{
Graft copolymerization of methyl acrylate onto sago starch using ceric ammonium nitrate as an initiator
}

\begin{abstract}
The graft copolymerization of methyl acrylate onto sago starch was carried out by a free radical initiating process. The free radicals were produced by the chemical initiation method in which ceric ammonium nitrate was used as an initiator. It was found that the percentages of grafting, grafting efficiency, and rate of grafting were all dependent on the concentration of ceric ammonium nitrate (CAN), methyl acrylate (MA), sago starch (AGU), mineral acid (H2SO4), and reaction temperature and period. The variables affecting the graft copolymerization were thoroughly examined. The optimum yield of grafting was obtained when the concentration of CAN, MA, AGU, and H2SO4 were used at $8.77 \times 10 \overline{1} 3,0.803$, 0.135 , and $0.175 \mathrm{~mol} \mathrm{Lī} 1$, respectively. The optimum reaction temperature and period were $50^{\circ} \mathrm{C}$ and $60 \mathrm{~min}$, respectively. The rate of graft polymerization was explored on the basis of experimental results and reaction mechanism. The evidence of grafted copolymers was investigated by using FTIR spectroscopy, TG, and DSC analysis.
\end{abstract}

Keyword: Graft copolymerization; Sago starch; Free radical; Monomer and poly(methyl acrylate) polymer 